\title{
Errata: Target detection and quantification using a hybrid hand-held diffuse optical tomography and photoacoustic tomography system
}

Patrick D. Kumavor, Chen Xu, Andres Aguirre, John Gamelin, Yasaman Ardeshirpour, Behnoosh Tavakoli, Saeid Zanganeh, Umar Alqasemi, Yi Yang, and Quing Zhu

University of Connecticut, Electrical and Computer Engineering Department, 371 Fairfield Way, Unit 2157 Storrs,

Connecticut 06269

[DOI: $10.1117 / 1.3587643]$

This article [J. Biomed. Opt. 16, 046010 (2011)] was originally published online on 7 April 2011 with an error in the $x$ axis label of Fig. 2. The frequency should read (MHz). The corrected figure appears below.

All versions of the article were corrected on 20 April 2011. It appears correctly in print.

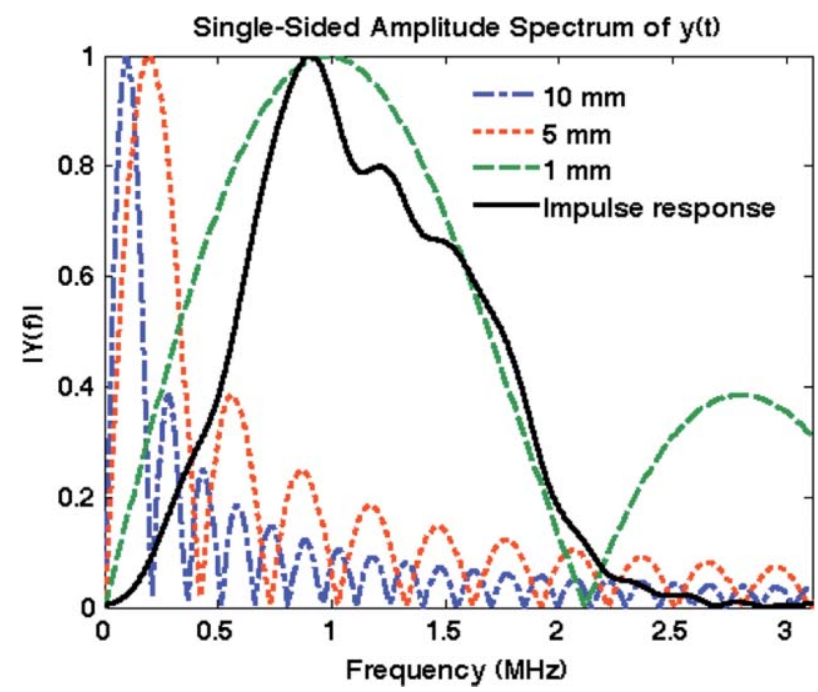

Fig. 2 Impulse response of the photoacoustic system along with the theoretical spectra for uniformly absorbing spheres with radii of 1,5 , and $10 \mathrm{~mm}$. 